\title{
Review on: Construction Technique of Hyperbolic Cooling Tower
}

\author{
Pranali M. Fulzele ${ }^{1}$, R.V.R.K Prasad ${ }^{2}$ \\ ${ }^{1}$ PG Student, ${ }^{2}$ Associate Professor, KDK College of Engineering, Nagpur (Maharashtra) India
}

DOI: 10.46335/IJIES.2020.5.9.2

\begin{abstract}
Natural draught cooling towers are exceptionally regular in present days into the nuclear and thermal power stations. They contribute towards a proficient energy output and the cautious balance with the atmosphere. These towers having extremely smaller thickness shell are excellent structures on the basis of sheer size and affectability to flat loads. Hyperbolic cooling towers are a fundamental component of thermal power plants. Hyperbolic cooling towers are mostly utilized shape amongst natural draught cooling towers. The taller high thicker tower exposed to the dynamic loads and personal weight. The paper presents the overview in the field of cooling towers and gives knowledge into the most recent improvements of the natural draught cooling towers. Distinctive modeling, analysis and design technologies are summed up and the difficulties faced are discussed. Further it gives the variety of the examinations accomplished for cooling towers and would provides a restructured data for the analysts and designers working in a field of hyperbolic cooling towers.
\end{abstract}

\section{INTRODUCTION}

Cool of power generation systems they also contribute to environment protection. The hyperbolic cooling towers are associated with nuclear and thermal power plants, although they are also used to some extent in some large chemical and other industrial plants. From the structural point of view they are high rise reinforced concrete structures in the form of doubly curved thin walled shells of complex geometry and so is their analysis and design. The in-plane membrane actions primarily resist the applied forces and bending plays the secondary role in these special structures. Development of cooling towers goes back to the $19^{\text {th }}$ century when the condensers were used with the steam engine (1902). The first hyperboloid shaped cooling tower was introduced by the Dutch engineers Frederik van Iterson and Gerard Kuypers and built in 1918 near Heerlen having 35 meter height. The first ones with 68 meter height in the United Kingdom were built prior to 1930 in Liverpool, England. Soon, heights and capacities increased, and the first cooling tower of height higher than 100 meter constructed in High Marnham Power Station in Britain. The cooling tower of 200 meter height built in 2002 in Niederaussem power station, Germany, was the world tallest hyperbolic cooling tower in the world until the construction of Kalisindh thermal energy plant in Rajasthan, India completed in June 2012. Two towers in this plant (Fig. 1) have a height of 202 meters with the base diameter of 142 meter each. 


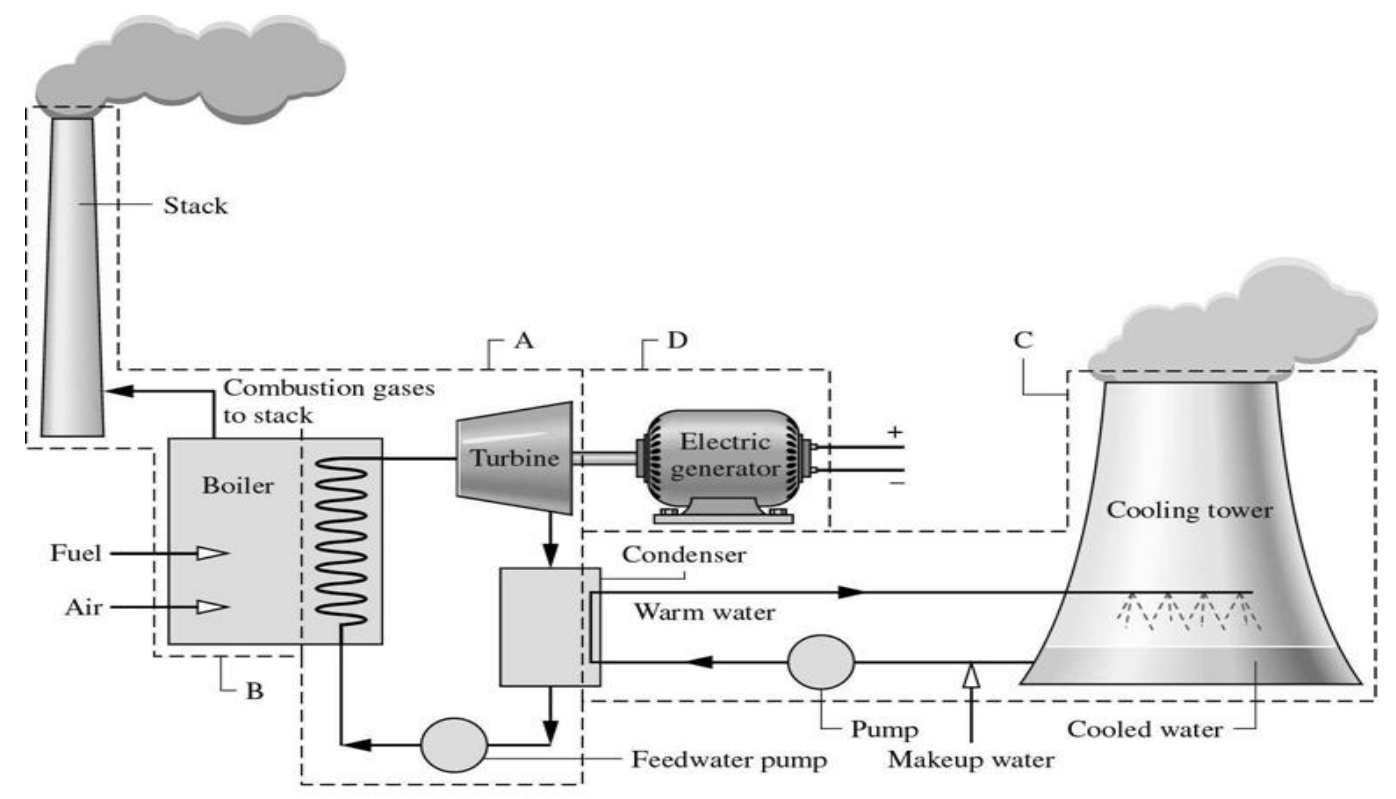

Fig 1- Typical schematic of thermal power plant

Natural draught cooling towers are most effective measures for cooling of thermal power plants by minimising the need of water and avoiding thermal pollution of natural water bodies. Thus they are able to balance environmental factors, investments and operating costs with the demands of a reliable energy supply.

Cooling towers in fossil fired power plants mostly do not only perform the refrigeration of the cooling water, they as well can be used for the discharge of the cleaned fluegases, with the benefit to completely save a chimney. This is a speciality of modern European power plants.
Figure 1 gives an impression about the last cooling tower projects already built or under construction in Germany. The power plants will have a total electrical power of about $6 \mathrm{GW}$ and are fired by lignite coal (Boxberg, Neurath and Niederaußem) or hard coal (Datteln and Hamm). Further projects of hard coal fired power plants in Moorburg, Lünen, Wilhelmshaven, Mainz, Maasvlakte, Antwerpen and Staudinger are projected or under construction and exposed to be finished till 2014 a giant power plant renewal program for Germany.

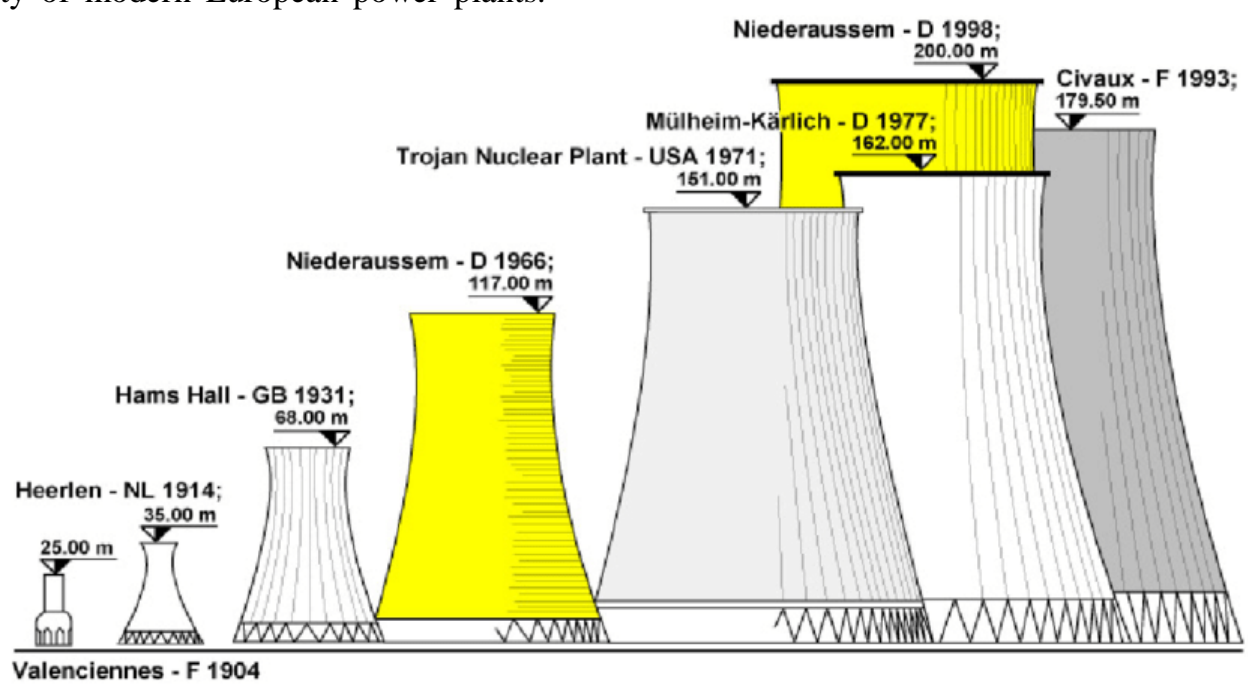

Fig 2 - Historical development of Natural draft cooling tower 
Figure 2 summarizes the historical development of natural draft cooling towers. Technical cooling devices first came into use at the end of the 19th century. The well-known hyperbolic shape of cooling towers was introduced by two Dutch engineers, Van Iterson and Kuyper, who in 1914 constructed the first hyperboloid towers which were $35 \mathrm{~m}$ high. Soon, capacities and heights increased until around 1930, when tower heights of $65 \mathrm{~m}$ were achieved. The first such structures to reach higher than $100 \mathrm{~m}$ were the towers of the High Marnham Power Station in Britain. Today's tallest cooling towers, located at several EDF nuclear power Plants in France, reach heights of about $170 \mathrm{~m}$. And it is predicted that $200 \mathrm{~m}$ high towers will be constructed in the early $21 \mathrm{st}$ century.

\section{II- TYPES OF COOLING TOWERS}

The classification of the cooling tower is as shown in figure 3:

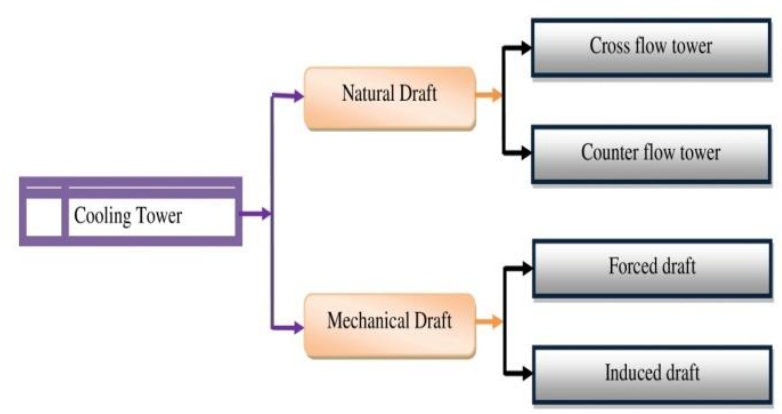

Fig 3-Classification of cooling tower

\subsection{NATURAL DRAFT COOLING TOWER:}

The natural draft or hyperbolic cooling tower makes use of the difference in temperature between the ambient air and the hotter air inside the tower. Schematic of natural draft or hyperbolic cooling tower is shown in figure 4 (a). As hot air moves upwards through the tower (because hot air rises), fresh cool air is drawn into the tower through an air inlet at the bottom. Due to the layout of the tower, no fan is required and there is almost no circulation of hot air that could affect the performance. Concrete is used for the tower shell with a height of up to $200 \mathrm{~m}$. These cooling towers are mostly only for large heat duties because large concrete structures are expensive. There are two main types of natural draft towers as cross flow tower and counter flow tower. In cross flow tower air is drawn across the falling water and the fill is located outside the tower whereas in counter flow tower air is drawn up through the falling water and the fill is therefore located inside the tower, although design depends on specific site conditions.

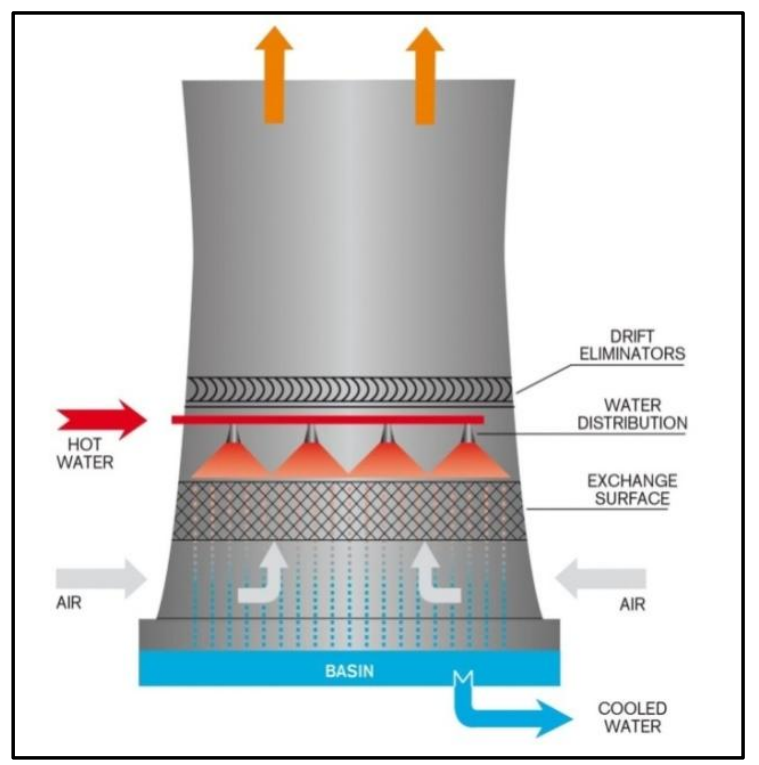

(a)

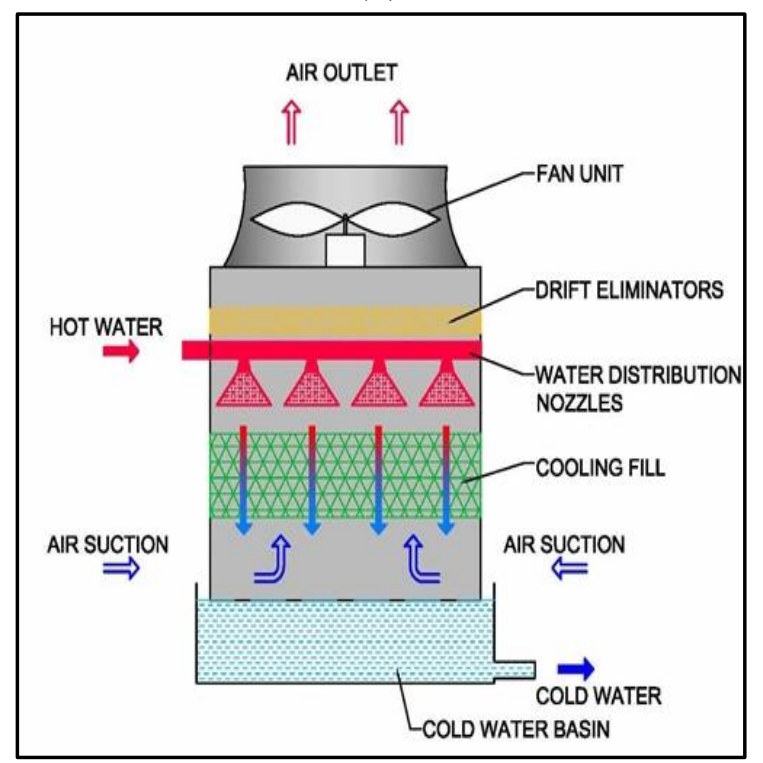

(b)

Fig 4-Schematics of (a) Natural draft cooling tower (b) Mechanical draft cooling tower

\subsection{MECHANICAL DRAFT COOLING TOWER:}

Because of their huge shape, construction difficulties and cost, natural draft towers have been replaced by mechanical draft towers in many installations. Schematic of mechanical draft hyperbolic cooling tower is shown in figure 4 (a). Mechanical draft towers have large fans to 
force or draw air through circulated water. The water falls downwards over fill surfaces, which helps increase the contact time between the water and the air. Cooling rates of mechanical draft towers depend upon various parameters; such as fan diameter and speed of operation, fills for system resistance, etc. There are two different classes of mechanical draft cooling towers as forced draft and induced draft.

\section{III- FINITE ELEMENT MODELING}

In 1967, the first cooling tower shell analyzed by means of a shell bending theory [1]. Later, Antonov [2] neglecting the tangential displacements and their derivatives in the geometrical equations of a bending shell theory used a fourth- order ordinary differential equation for the normal displacement. In the 1970s, the FEM began to enter into the analysis of hyperbolic cooling tower shell structures. First, flat triangular finite elements were used. Lochner [3] applied a three-node curvilinear triangular shell element. A year later, using the FEM, Konderla considered the numerical solutions of symmetrical [4] and asymmetrical [5] problems of hyperbolic shells of revolution within the limits of a geometrically nonlinear shell theory. Detailed investigations on the finite element modeling and suitable elements applied in cooling towers analysis are covered in [6]-[9].

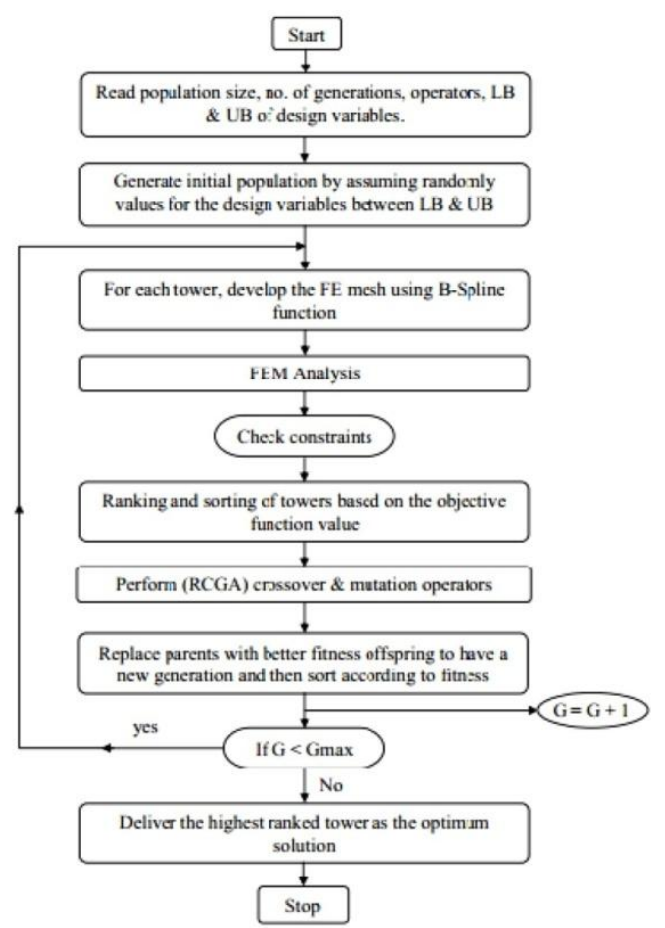

Fig. 5 - Flow chart for optimum shape and design of cooling towers [10].

\section{IV- NONLINEARITY AND ULTIMATE LOAD}

For the last four decades, tensile cracking in the concrete has been employed in the finite element analyses of RC structures. To this end, two distinct models being complex and time consuming have been generally employed: the discrete- cracking model and the smearedcracking model. Various nonlinear factors, such as the material nonlinearities in the concrete and reinforcing steel, tensile cracking, the bond effects between concrete and steel in the cracked concrete which is known as the tension stiffening, the large displacement effects, and so on; need to be taken into account to investigate the ultimate behavior of such structures.

Based on the Finite Element Method (FEM) a comprehensive numerical investigation of a RC hyperbolic cooling tower at Port Gibson, Miss. USA, was reported by Mang et al. [11]. They analyzed the cooling tower shell considering the large displacement, cracking in concrete, steel yielding and inelastic behavior of concrete. In their study, it was suggest that, in evaluating the ultimate strength of the cooling tower shell, the full nonlinear analysis must be performed since the ultimate load factor obtained by the nonlinear analysis is shown as considerably lower than that obtained by the buckling analysis. Milford and Schnobrich [12] obtained the load factor of 2.1 considering the tension stiffening effect, crack rotation and the geometrical nonlinearity. Later studies carried out by Hara et al. [13], Min [14] and Noh [15] reported the same conclusion. Thirty years later, Jia [16] employing another program, analyzed the same tower using the finite element method to find out whether the conclusions based on these results still hold if the concrete with much higher strength is used and geometric imperfections are considered. However, Mahmoud and Gupta [17] obtained a load factor of 1.73 taking into account the large displacement effects. They concluded that the failure of the Port Gibson Tower at 
Mississippi was caused by the circumferential buckling in the vicinity of the throat rather than the yielding of the reinforcement, which contradicts the results of the previous researchers.

\section{V- LOADING, ANALYSES AND RESPONSES}

The NDCT shell structures are submitted to environmental loads such as wind, earthquake and thermal gradients that are stochastic in nature. The dead loads, settlement, and construction load are the other common load conditions and various accidental loads, e.g., explosion often experience by hyperbolic cooling towers in their lifetime. The effects of the various loading conditions are combined and factored according to the available codes for the analysis and design purposes. Dead load consists of the self-weight of the tower shell wall, the ribs, and the superimposed load from attachments and equipment. In the vicinity of the top edge, the self weight of the tower produces membrane tension however an axisymmetric and nearmembrane state of compression are attained in the entire shell and in the vicinity of the supports, some bending may occur [18], [19]. The self weight for the towers of a general shape considering a number of different patterns of shell- thickness variation along a meridian was studied by Zingoni [18]. The meridional directed forces developed in tower shell due to the self-weight of the tower may cause local (diamond-shaped) buckling or axisymmetric circular buckling [1]. For NDCT shell structures self-weight is always studied in combination with wind load in the areas of negligible seismic activity. Overall buckling of the tower shell may caused by combination of wind load and self-weight which takes place with large displacements. There is a considerable difference between design codes in criteria for buckling safety, requiring either the "snap-through" approach proposed by Der and Fidler [20] and used in British, Indian and German codes, the local or "buckling stress states" (BSS) approach proposed and developed by
Mungan [21]-[23] and also used in German code, or the global approach which requires a full nonlinear buckling analysis of the shell and preferred in USA code [24].

\section{VI- WIND AND BUCKLING OF THE TOWER}

Wind is the prime lateral load and its combination with self weight of the tower shell can cause the buckling instability leading to catastrophic failure. After the sudden collapse of three immense cooling towers at Ferry-Bridge Power Station in England in 1965, experimental and theoretical investigations had been done in the area of the stability of hyperbolic shells to study the parameters increasing the wind resistance and buckling safety of the cooling towers. Niemann et al. [25] assessed the wind loads on the cooling towers using a new approach with individual equivalent static loads, and presented the design of the reinforcement in the meridional /circumferential direction and the design against buckling. Karisiddappa, et al. [26] carried out the analysis of column supported cooling towers for unsymmetrical wind loads. Improved 3D finite element formulation of column supported hyperbolic cooling towers and the realistic circumferential wind pressure distribution was carried out. Consequently, for different wind pressure distribution profiles, meridian membrane forces were shown to exhibit more sensitivity towards the pressure variations. Buckling is one of the main failure considerations in design of the cylindrical and hyperbolic shells. Vaziri et al. [27] reported that the sensitivity of the buckling behavior of both plates and shells in the presence of defects such as cracks highly depends on the loading condition. The uniform external pressure at which a cylindrical shell buckles is very sensitive to the geometry of the cylinder. The buckling strength drops rapidly as the buckle becomes longer making longer cylinders have a lower critical buckling pressure. The buckling strength is also affected by the thickness of the cylinder and thinner cylinders have lower critical buckling pressures [28]. 
The wind-induced response of cooling tower is the key factor to improve safety and to reduce tower crack [29]. At present, the research on the large cooling towers is focused on the material properties of the shell structure of tower, such as multi-layered nonlinear concrete shell [29], and the structural behaviour under external environment [30], [31] especially under wind loads.

Wind load analysis can be performed following three methods. One is from experiments wind pressure coefficient, the shape factors and the wind-induced vibration coefficient can be obtained [32], [33]. Two is the CFD (computational fluid dynamics) analysis, to calculate the wind pressure and velocity distribution directly with the appropriate turbulence models [34], [35]. And the three is, to perform spectral analysis with a variety of wind spectra of the tower.

Goudarzi et al. [36], [37] investigated the effects of NDCT geometry features on formation of pressure field around the Kazerun power plant in Iran.

\section{VII- COOLING TOWER EFFICIENCY}

Cooling tower is normally designed for stagnant ambient air condition, but experimental observation showed that cooling efficiency was changed as a function of crosswind velocity. Cooling efficiency of a natural draft cooling tower (NDCT) is significantly affected under cross-wind condition and might decrease to 75 percent in the range of moderate to high wind- velocity condition. Separated flow occurring at the rear radiators, along with deflected plume exiting tower stack, reduces the cooling efficiency [38]. Experimental and numerical observations identically showed that heat transfer capacity of the cooling tower proportionally increased with wind velocity up to $3 \mathrm{~m} / \mathrm{s}$, and then decreased for higher wind velocity [39]. Various researchers have studied the effect of the wind on cooling tower's efficiency and the methods of the improvements. The first numerical study was performed by Du Preez and
Kroger [40] to illustrate the wind effect on air flow field through the cooling tower. Other researchers identically showed that there were two causes which reduced the cooling efficiency; flow acceleration near the sideward radiators trailing with a flow separation beside the rearward radiators, and plume deflection at the exit plane of the tower stack [41]. The same unfavorable crosswind effects were reported in [42]-[44] on the thermal performance of a natural draft wet cooling tower.

\section{VIII- CONCLUSION}

The latest theatrical and experimental improvements and new achievements in the analysis and design of the natural draft hyperbolic cooling towers are briefly discussed. The various factors in the analysis and design of the cooling towers have been tracked in this study. This review is a complete collection of the studies done for cooling towers and would give the updated and sufficient materials for the researches in this field.

\section{REFERENCES}

[1] S.N. Krivoshapko,"Static, vibration, and buckling analyses and applications to one-sheet hyperboloidal shells of revolution," American Society of Mechanical Engineers, vol. 55, no.3, pp. 241-270, 2002.

[2] E.N. Antonov, "On analysis of a hyperboloidal cooling tower shell subjected to axisymmetrical loading, "Sb. trudov LISI, vol. 63, pp. 107- 112 (in Russian) 1970.

[3] N. Lochner, "Die Anwendung des Schalen elements, " SHEBA, Finite Element Static, Berlin, 1973, pp. 353-372.

[4] P. Konderla, "Nieliniowe rozwiazanie powloki o ksztalcie hip-erboloidy jednopowlokowej Cz.I, obciazenie osiowosymetryczne," Arch. inz. lad, vol. 20, no. 3, pp. 501-515 (in Polish), 1974.

[5] P. Konderla, "Nieliniowe rozwiazanie powloki o ksztalcie hiperboloidy jednopowlokowej, Cz.II, obciazenie niesymetryczne," Arch. inz. lad, vol. 20, no. 3, pp. 517533 (in Polish), 1974.

[6] T.Y. Yang, and K. K. Rakesh, "Shell Elements for Cooling Tower Analysis, " J. Eng. Mech, vol. 109, no. 5, pp. 1270 1289, 1983. 
[7] S.S.J. Moy, and S.M. Niku, "Finite element techniques for the analysis of cooling tower shells with geometric imperfections," Thin - Walled Structures, vol. 1, no. 3, pp. 239-263, 1983.

[8] R.L. Nelson, and D.L. Thomas, "Free vibration analysis of cooling towers with column supports," Journal of Sound and Vibration, vol. 57, no. 1, pp. 149-153, 1978.

[9] M. Özakça, and E. Hinton, "Free vibration analysis and optimisation of axisymmetric plates and shells-I. Finite element formulation," Computers \& Structures, vol. 52, no. 6, pp. 1181-1197, 1994.

[10] A.M. El Ansary, A.A. El Damatty, and A. O. Nassef, "Optimum Shape and Design of Cooling Towers," World Academy of Science, Engineering and Technology, vol. 5, no, 12-21, 2011

[11] H. A. Mang, H. Floegl, F. Trappel, and H. Walter, "Windloaded reinforced concrete cooling towers: buckling or ultimate load?, " Engineering Structures, vol. 5, no. 3, pp. 163-80, 1983.

[12] R.V. Milford, and W.C. Schnobrich, "Nonlinear behavior of reinforced concrete cooling towers," Civil Engineering Studies structural research series no. 514. University of Illinois, 1984.

[13] T. Hara, S. Kato, and H. Nakamura, "Ultimate strength of $R C$ cooling tower shells subjected to wind load," Engineering Structures, vol. 16, no. 3, pp. 171-180, 1994.

[14] C. S. Min, "Design and ultimate behavior of RC plates and shells," Nuclear Engineering and Design, vol. 228, no. 1-3, pp. 207-223, 2004.

[15] H. C. Noh, "Ultimate strength of large scale reinforced concrete thin shell structures, " Thin-Walled Structures, vol. 43, no. 9, pp.1418-1443, 2005.

[16] X. Jia, "Revisiting the failure mode of a RC hyperbolic cooling tower, considering changes of material and geometric properties," Engineering Structures, vol. 47, pp. 148-154, 2013.

[17] B.E.H. Mahmoud, and A.K. Gupta, "Inelastic large displacement behavior and buckling of cooling tower," Journal of Structural Engineering, ASCE, vo. 121, no. 6, pp.981-985, 1995.

[18] A. Zingoni, Self-weight Stresses in Hyperbolic Cooling Towers of General Shape, International Journal of Space Structures, 1999, 14 (4), 281-294.

[19] Zingoni A., "Shell structures in civil and mechanical engineering" London: Thomas Telford; 1997.
[20] T.J. Der, and R. Fidler, "Model study ofthe buckling behaviour of hyperbolic shells," Proceedings of the Institution of Civil Engineers, 1968, vol. 41, pp. 105-118.

[21] I. Mungan, "Buckling stress states of hyperboloidal shells, " ASCE Journal of Structural Engineering, vol. 102, no. 10, 2005-2020, 1976.

[22] I. Mungan, "Basic aspects of buckling of cooling tower shells," ASCE Journal of Structural Engineering, vol. 107, no. 3, pp. 521-534, 1981.

[23] Mungan, I., "Buckling of reinforcedconcrete cooling tower shells", BSS approach, ACI Journal 1982, 88(3), 387-391

[24] Bamu and Zingoni, "Damage, deterioration and the longterm structural performance of cooling-tower shells: A survey of developments over the past 50 years," Engineering Structures, vol. 27, pp. 1794-1800, 2005.

[25] H. Niemann, and M. Kasperski, "The assessment of wind loads on cooling towers, builds aerodynamics laboratory," Ruhr University at Bochum, Germany, 1990, pp. 101-112.

[26] P. Karisiddappa, P.N. Godbole, J. Noorzaei, "Analysis of column supported cooling tower for unsymmetrical wind loads," Ninth ICWE Conference on Wind Engineering, 1995, vol. 3, pp. 1523-1531.

[27] A. Vaziri, and H.E. Estekanchi, "Buckling of cracked cylindrical thin shells under combined internal pressure and axial compression," Thin- Walled Structures, vol. 44, no. 2, pp. 141-151, 2006.

[28] C. Lei, J. Michael Rotter, and D.S. Cornelia, "Practical calculations for uniform external pressure buckling in cylindrical shells with stepped walls," Thin-Walled Structures, vol. 61, no. 2, pp. 162-168, 2012.

[29] W. F. Chen, and M.L. Eric, "Handbook of structural engineering," CRC Press, Boca Raton, New York 2005.

[30] Z. Waszczyszyn, E. Pabisek, J. Pamin, and M. Radwan'ska, "Nonlinear analysis of a RC cooling tower with geometrical imperfections and a technological cutout," Engineering Structures, vol. 22, no. 5, pp. 480- 489, 2000 .

[31] M. N. Viladkara, P.B. Karisiddappa, and P.N. Godbole, "Static soil- structure interaction response of hyperbolic cooling towers to symmetrical wind loads," Elsevier, Engineering Structures, vol. 28, no. 9, pp. 1236-1251, 2006.

[32] J. Noorzaei, A. Naghshineh, M.R. Abdul Kadir, W.A. Thanoon, and M.S. Jaafar, "Nonlinear interative analysis of cooling tower-foundation- soil interaction under 
unsymmetrical wind load," Thin-Walled Structures, vol. 44, pp. 997-1005, 2006.

[33] Y. J. Shi, and D.Z. Wang, "Test method of cooling tower," Thermal Power Generation, vol. 9, pp. 1-311979.

[34] J. Y. Li, C.L. Ren, and Z.L. Huang, "Experiment study and finite element analysis of a natural draft cooling tower," Chinese Quarterly of Mechanics, vol. 3, no. 28, pp. 443447, 2007.

[35] A. W. Rafat, and B.Masud, "Cross winds effect on the performance of natural draft wet cooling towers," International Journal of Thermal Sciences, vol. 49, pp. 218-224, 2010.

[36] R. Meroney, "CFD prediction of cooling tower drift," Journal of Wind Engineering and Industrial Aerodynamics, vol. 94, pp. 463-490, 2006.

[37] M. A. Goudarzi, S.R. Sabbagh-Yazdi, "Effects of modeling strategy on computational wind pressure distribution around the cooling towers," Wind and Structures, vol. 14, no. 1, pp. 81-84, 2011.

[38] M. Goodarzi, "A proposed stack configuration for dry cooling tower to improve cooling efficiency under crosswind," J Wind Eng Ind Aerodynam, vol. 98, pp. 858$863,2010$.

[39] N. Kapas, "Behavior of Natural Draught Cooling Towers in Wind," CMFF, Budapest, Hungary, 2003, 30

[40] A.F. Du Preez, D.G. Kroger, "Effect of wind performance on a dry cooling tower," J. Heat Recovery Syst. CHP, vol.13, no. 2, pp. 139-146, 1993.

[41] R. Al-Waked, and M. Behnia, "The performance of natural draft dry cooling towers under crosswind: CFD study," Int J Energy Res, vol. 28, pp. 147-161, 2004.

[42] M.N.A. Hawlader, and B.M. Liu, "Numerical study of the thermal- hydraulic performance of evaporative natural draft cooling towers," Appl Therm Eng, vol. 22, pp. 4159, 2002.

[43] R. Al-Waked, M. Behnia, "CFD simulation of wet cooling towers," Appl Therm Eng, vol. 26, pp. 382-395, 2006. [113] N. Williamson, S. Armfield, and M. Behnia, "Numerical simulation of flow in a natural draft wet cooling tower - the effect of radial thermo- fluid fields," Appl Therm Eng, vol. 28, pp. 178-189, 2008.

[44] Z. Zhai, and S. Fu, "Improving cooling efficiency of drycooling towers under cross-wind conditions by using wind-breaker methods," Appl Therm Eng, 2006, 26, 1008-1017. 